\title{
Virtual Dissection Table Including the Visible Korean Images, Complemented by Free Software of the Same Data
}

\author{
Mesa de Disección Virtual que Incluye las Imágenes de Visible Korean, \\ Complementadas por Programa de Libre Acceso con Igual Información
}

\author{
Beom Sun Chung*; Dong Sun Shin"*; Paul Brown"**; Jack Choi***** \& Min Suk Chung*
}

CHUNG, B. S.; SHIN, D. S.; BROWN, P.; CHOI, J. \& CHUNG, M. S. Virtual dissection table including the Visible Korean images, complemented by free software of the same data. Int. J. Morphol., 33(2):440-445, 2015.

SUMMARY: The objective of this study was to introduce the complementary relationship between virtual dissection table (simply, table) and free software, since authors tried to aid interested people in their studying digital human anatomy. Visible Korean (VK) team had presented the serially sectioned images and outlined images of a male cadaver. Thereafter, Anatomage (San Jose, CA) manufactured the table by making 3-dimensional (3D) volume models from the data. Separately, the VK team reconstructed surface models from the same data and inputted the models in portable document format (PDF) file, which can be opened on the personal computer. The software to browse the sectioned and outlined images was also programmed by VK team. In this report, the table and the VK free software were compared to establish their supplementary potentiality. Both the table and free software displayed equivalent 3D models reconstructed from the same sectioned images. In both platforms, the models were labeled for users to recognize the individual structures. Both the table and the free software had respective features to enhance the virtual dissecting experience. The table came with its designated hardware with life-sized display, whereas VK software could be run in any personal computer without burden. The coexistence of the table and free software will enrich the people learning anatomy. With increasing VK data and free software, more and more commercial or complimentary products are expected to be produced.

KEY WORDS: Visible Human Projects; Anatomic models; Computer simulation; Cadaver.

\section{INTRODUCTION}

Virtual dissection table (simply, table) produced by Anatomage company (San Jose, CA, United States) is reputed for the advanced hardware and refined computational algorithm to handle three-dimensional (3D) volume models (Fyfe et al., 2013). Another discriminative factor, compared to its competitors, is that the table includes Visible Korean (VK) sectioned images of a male cadaver comprising high resolution and real color (Park et al., 2005). The VK outlined images have successively been applied to the table, enabling identification of hundreds of structures on the volume models.

Meanwhile, the VK team produced 3D surface models with the same data. The surface models were put into the portable document format (PDF) file which can be opened on Adobe Reader version 9 (Adobe Systems, Inc., San Jose) (Shin et al., 2012b). Additional software was elaborated to browse the 2-dimensional (2D) sectioned and outlined images (Shin et al., 2011). Both have been distributed gratis on VK website (anatomy.co.kr).

The purpose of this research is to inform people, interested in the digital human anatomy, of the compensatory relationship between the table and the free software. We compared the function and usage environment of these two systems, and researched the possibility to manufacture other virtual reality anatomy programs.

\footnotetext{
* Department of Anatomy, Ajou University School of Medicine, Suwon, Republic of Korea.

** Department of Orthopaedic Biomaterial Science, Graduate School of Medicine, Osaka University, Osaka, Japan.

*** Division of Anatomy, School of Medicine, Stanford University, Palo Alto, United States.

***** Anatomage, San Jose, United States.

This research was supported by Basic Science Research Program through the National Research Foundation of Korea (NRF) funded by the Ministry of Education (grant number 2010-0009950).
} 


\section{MATERIAL AND METHOD}

A 33-year-old male cadaver, donated for medical research and education with the consent of his family, was chosen as the first subject of the VK project.

After postmortem computed tomography (CT) and magnetic resonance imaging (MRI) scan, the cadaver was embedded in a fresh state and serially sectioned at $0.2 \mathrm{~mm}$ intervals. Each sectioned surface was digitally photographed to produce 8,510 sectioned images (pixel size $0.2 \mathrm{~mm} ; 24$ bits color) (Park et al.). Subsequently, the 1,702 sectioned images were selected at $1 \mathrm{~mm}$ intervals for outlining. 937 structures were delineated almost manually over a period of eight years (Shin et al., 2012c).

The VK research team presented Anatomage company the full data of sectioned and outlined images not exclusively, since Anatomage was one of the groups interested in the VK. There were no contracts of commercial return between the VK team and Anatomage. The Anatomage utilized the data to reconstruct 3D volume models, which were applied to the table with distinguished hardware and software.

The VK team used the same data for reconstructing the 3D surface models which were put into the PDF file (Shin et al., 2013). Concurrently, the browsing software showing the corresponding sectioned images, outlined images, CTs, and MRIs was composed (Shin et al., 2011).

In this study, we attempted to identify the same structures in sectional planes and stereoscopic models, using the table, PDF file, and browsing software. We have found similarity and dissimilarity between the systems using recognition of the stomach as a demonstrative example.

\section{RESULTS}

If the $3 \mathrm{D}$ volume model of stomach was selected in the table, it was highlighted and its anatomical name consequently appeared on it. Alternatively, when the text menu of the stomach was selected from the list, the stomach's annotation appeared on its 3D model. The 3D surface models and model tree texts were correlated in a similar manner in the PDF file. Undoubtedly, the table and PDF file showed the identical 3D models corresponding to the same image source (Fig. 1).

The label of the stomach appeared when the mouse pointer was placed on the stomach in the horizontal sectioned images, both in the table and browsing software. In the PDF file, the users were able to recognize the stomach in the sectioned images by referring to the overlapped 3D surface model of the stomach (Fig. 2).

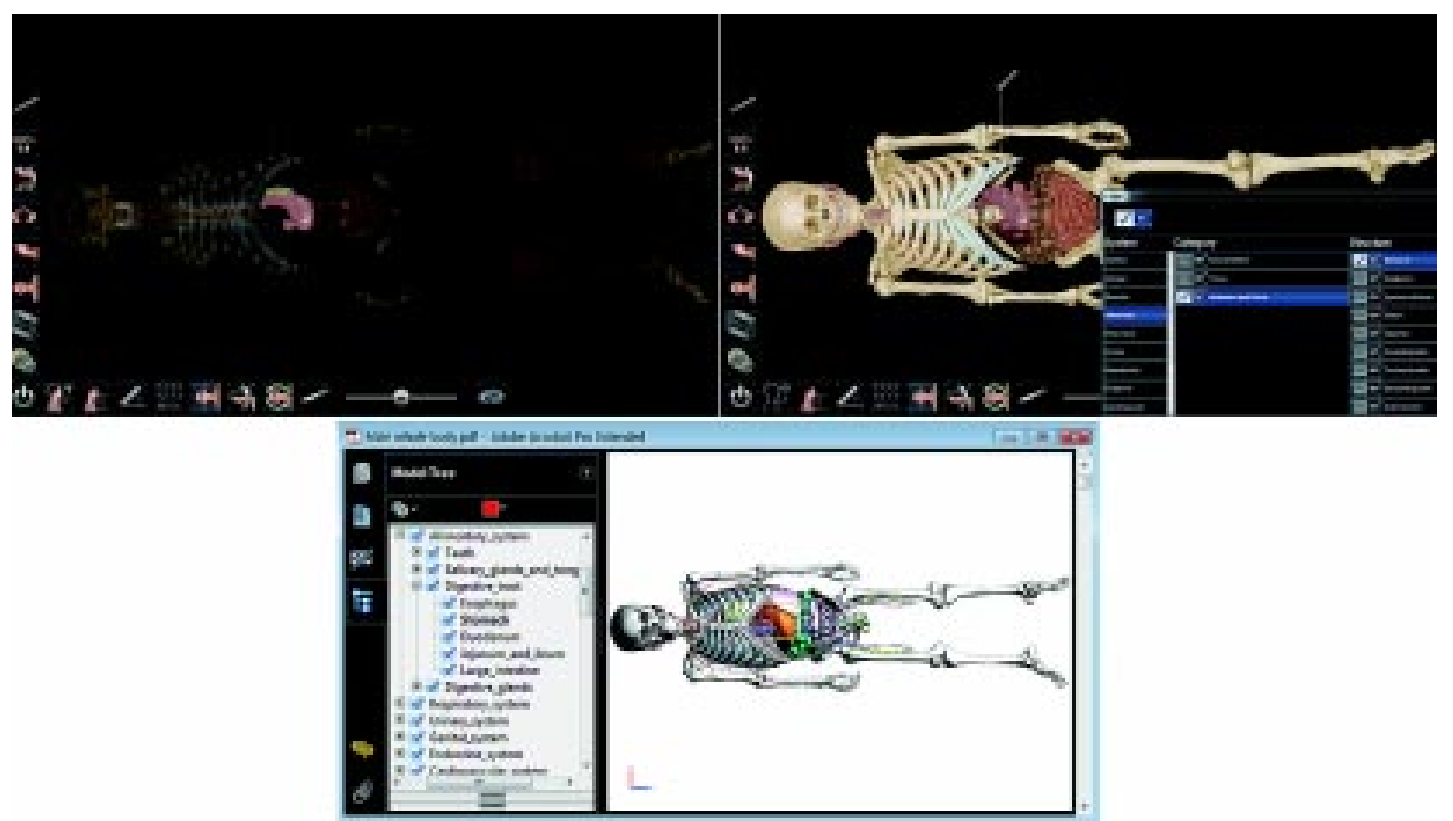

Fig. 1. Virtual dissection table (top) and PDF file (bottom) to identify the stereoscopic model of stomach. When the stomach's volume model is chosen, the model is highlighted and its name shows up (top left). Reversely, when stomach text is chosen, the stomach model is annotated (top right). When the stomach is selected either on the surface models or on the model tree texts, both are highlighted (bottom). 

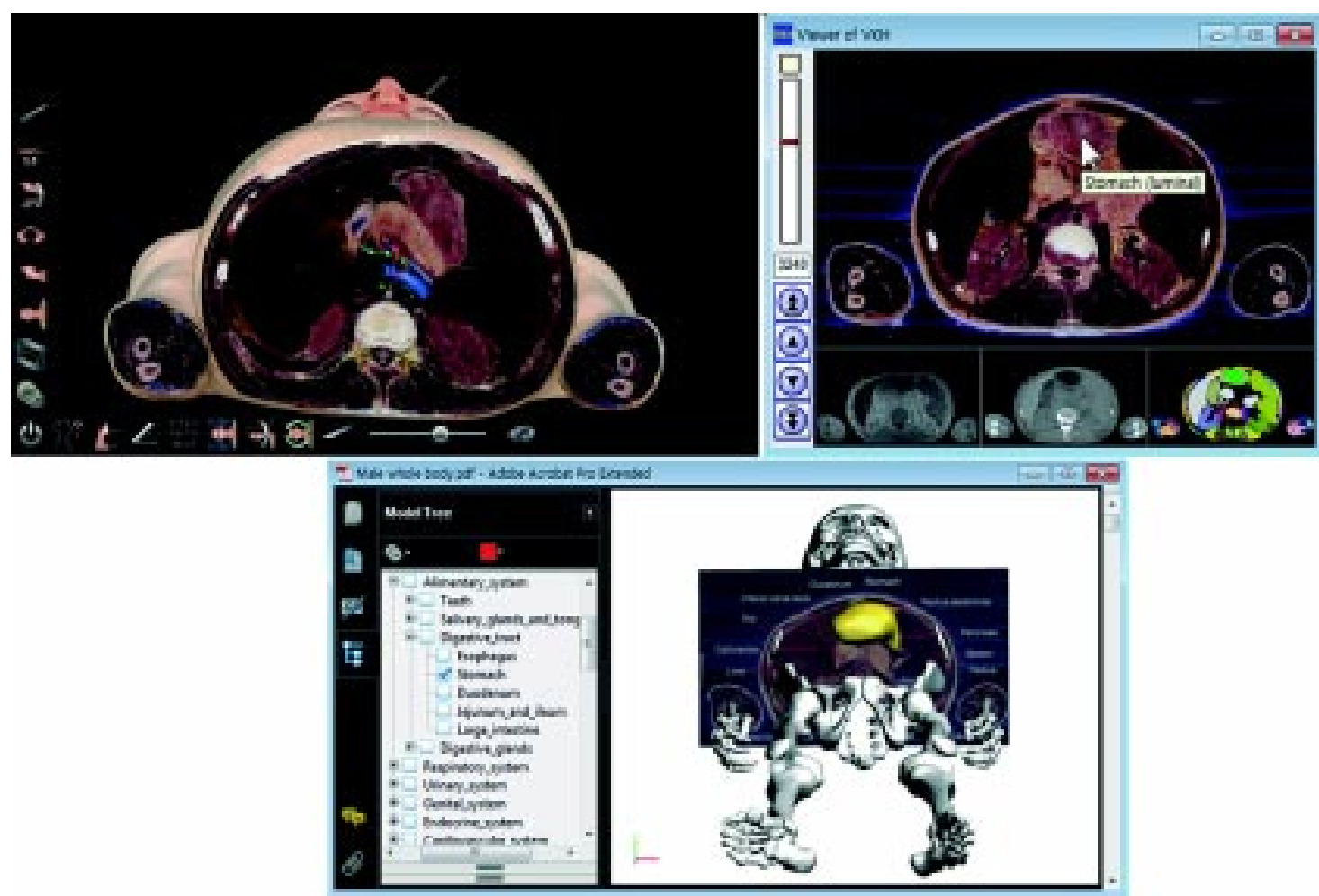

Fig. 2. Virtual dissection table, browsing software, and PDF file showing horizontal sectioned images containing the stomach. The selected stomach is automatically annotated in the table (top left) and browsing software (top right). The sectioned image containing the stomach is embedded to the surface models in the PDF file (bottom).

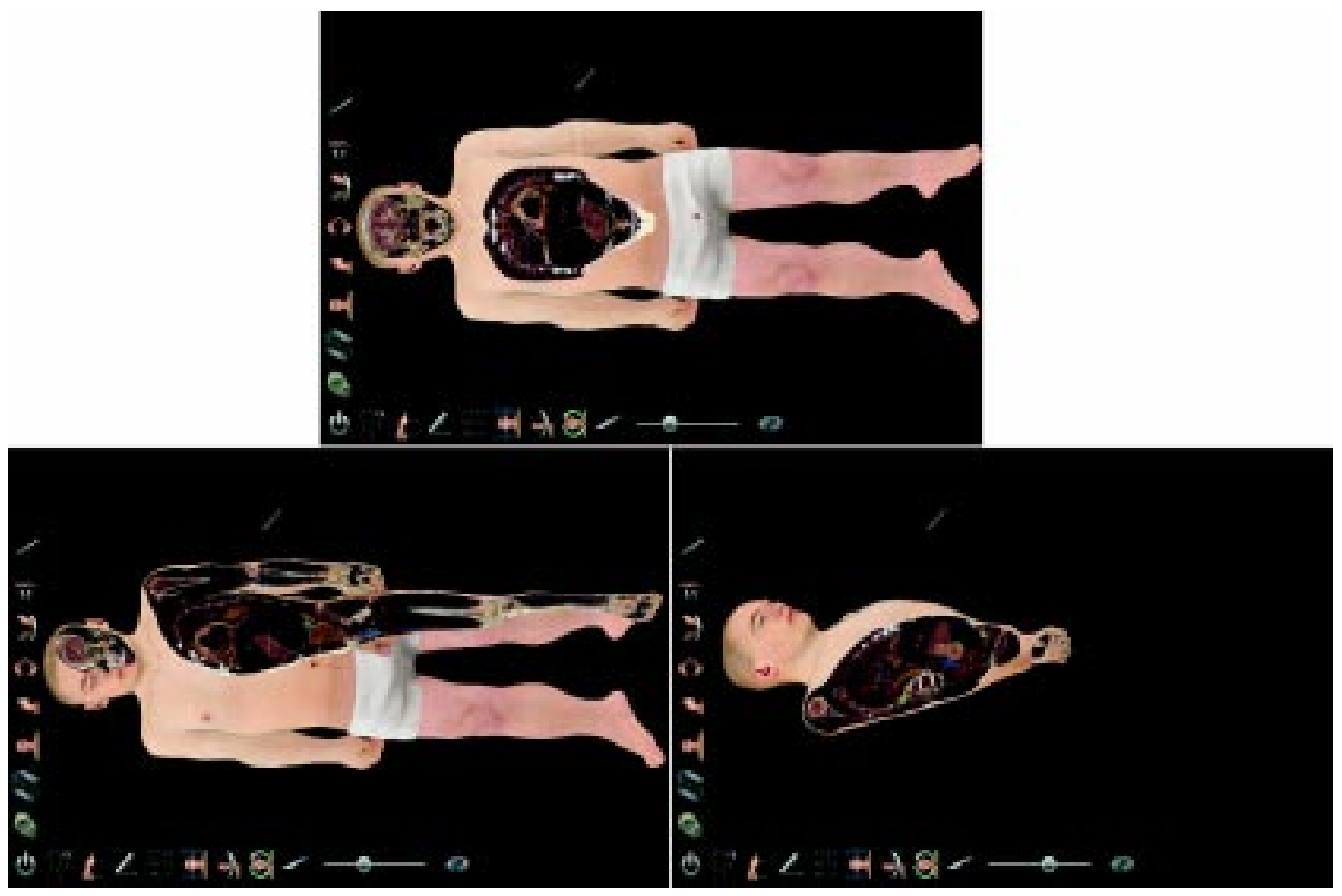

Fig. 3. Virtual dissection table showing the various planes containing the annotated stomach. 
The table had additional functions for user's convenience. Unlike the free software, the table provided sectioned images in arbitrary angles, where the stomach was annotated as well (Fig. 3). When the user selected a certain structure, other structures were made semitransparent (Fig. 1. top left). The users were able to peel the superficial structures sequentially in order to prominently display the cadaver's interior organs. Additionally, Anatomage company protected the privacy of the original subject. The developers modified the facial appearance of the subject and hid the external genitalia with a virtual towel. These virtues would help the users study anatomy with less discomfort (Fig. 3).

The PDF file and the browsing software also had their extra functions. Only desired regions such as head could be displayed in the PDF file, by the use of established bookmarks. The supplementary multimedia data such as a movie in the PDF file could be exhibited by selection of the appropriate pages (Shin et al., 2012b). In the browsing software, the users were able to choose the images either by using the scroll bar or by typing an image number. Neighboring images could be continuously shown by clicking the buttons (Fig. 2. top right) (Shin et al., 2011).

The table offered not only the VK images, but also the CTs from actual patients in normal or pathologic conditions. Moreover, the clients were able to load any medical images in digital imaging and communications in medicine (DICOM) standard to build their own 3D volume models. All of those models could be moved, rotated, and cut in like manner.

The browsing software contained the CTs and MRIs from the very cadaver. Therefore, the software permitted comparison of the clinical images with the high quality sectioned images (Fig. 2. top right) (Shin et al., 2011).

The table was equipped with the specialized display capable of showing human body in 1:1 life-size scale. The stereoscopic models were freely manipulated with the multifunctional touch screen. In the way, the table would give realistic dissecting experience to people who wanted the actual cadaver but had no opportunity.

Contrarily, the VK software was to be controlled on the average personal computer. So the software could be taken advantage of in the school, library, or even at home.

The 3D volume models resulted in not only the higher file size (approximately 60 GBytes), but also the immense number of processes for virtual dissection. Therefore, Anatomage applied the high performance hardware and efficient algorithm, enabling users to browse the human body quickly.
The VK free software contained 3D surface models (74 MBytes) or 2D images (335 MBytes) which are much smaller in file size than $3 \mathrm{D}$ volume models. The software could be downloaded to personal computer entirely to be used offline without delaying.

\section{DISCUSSION}

The VK images have various merits for the selection by Anatomage company. There are other challengers who make sectioned images from whole cadavers, such as Visible Human Project from the United States (Spitzer et al., 1996), and Chinese Visible Human (Zhang et al., 2006) and Virtual Chinese Human (Dai et al.; Tang et al., 2010). Only the VK data is made from a fresh un-embalmed cadaver, into which no dye was injected so that the data consists of realistic color and texture (Park et al.). Moreover, the VK team supplies the complete outlined images, despite the fact that the outlining took several years to be accomplished (Shin et al., 2012c).

Other investigators' software packages using Visible Human Project data set have several vulnerable points. Their browsing software requires installation of Java application and modification of security settings. To access the 3D models made from Visible Human Project data, one must register and $\log$ on to a website. Interface to manipulate the models is too complicated to be used by lay people. Moreover, operating 3D models on-line results in frequent loading time (Bessaud \& Hersch; Wetzel et al., 2000). So as to solve the issues, VK team has presented the simple and handy software to deal with 2D and 3D images of the human body.

The free software of VK data differs from the Anatomage table in its functions and usage environment. In general, the table comprises better functions than the free software. For instance, the Anatomage table shows reconstituted sectioned images in arbitrary planes, overlapped on 3D models (Fig. 3), while the free software exhibits original sectioned images only in horizontal plane (Fig. 2). However, experiencing the table first hand is permissible, only in schools or institutes having the table.

The free software from VK team can enhance the educational effect of the table. Participants can prepare the table-based lesson by using the VK software in advance. The VK software also permits people to review what they have learned on the table.

Unlike the table, the VK software can be easily modified by other developers. Even general users can make 
bookmarks for preferential display of body structures with the PDF file (Shin et al., 2013). The zoom-in function or the adjustment panel for brightness and contrast can be applied on the browsing software. The software has the potential to be converted for use on mobile devices like smart phones or tablet computers. The portability will enhance the convenience of the software to be utilized during anatomy lessons or cadaver dissections. All modified programs will accelerate the improvement of the table.

Hereafter, the development of the table and VK complimentary software will be accelerated by improving VK data set. We already have the sectioned images of the entire female body. The production of the outlined images and subsequent surface models of the female are currently underway. Additionally, existing sectioned and outlined images of male head and female pelvis can be provided to enhance the table (Shin et al., 2012a, 2013).

VK researchers have presented entire data as an open source to encourage numerous research and educational opportunities (Bichlmeier et al., 2008; Färber et al., 2009; Uhl et al., 2006). The final goal of the VK is not to make profit, but to assist others to develop useful educational materials. Alternate program development in competition with the previous commercial table and cost-free software, will likely have a great synergistic effect. These new products will be comparable, since they all derive from the identical data.

In conclusion, the table, free software, and other future programs, made with the VK data, advantageously influence and compensate each other. The users will benefit from an expanded range in choosing anatomy learning aids.

\section{ACKNOWLEDGEMENTS}

This research was supported by Basic Science Research Program through the National Research Foundation of Korea (NRF) funded by the Ministry of Education (grant number 2010-0009950).

Raw data of the Visible Korean were acquired by the financial assistance from the Korea Institute of Science and Technology Information.

CHUNG, B. S.; SHIN, D. S.; BROWN, P.; CHOI, J. \& CHUNG, M. S. Mesa de disección virtual incluyendo las imágenes de visible Korean, complementadas por programa de libre acceso con igual información. Int. J. Morphol., 33(2):440-445, 2015.

RESUMEN: El objetivo de este estudio fue introducir la relación complementaria entre una mesa virtual de disección (simplemente, la mesa) y un programa de libre acceso. Mediante este proceso los autores trataron de ayudar a aquellas personas interesadas en el estudio de la anatomía humana digital. El equipo Visible Korean (VK) había presentado las imágenes de secciones consecutivas e imágenes de un cadáver de sexo masculino. Partiendo de ese punto, la compañía Anatomage fabricó la mesa produciendo con los datos modelos dimensionales de volumen (3D). En forma paralela, el equipo VK reconstruyó los modelos de superficie con los mismos datos y de entrada de los modelos en formato de documento portátil (PDF), que se pudieran abrir en el ordenador personal. El equipo VK además lo programó para navegar a través de las imágenes seccionadas y descritas. En este informe, la mesa y el programa VK fueron comparados para establecer su potencialidad complementaria. Tanto la mesa como el programa de libre acceso muestran modelos 3D equivalentes reconstruidos a partir de las mismas imágenes seccionadas. En ambas plataformas, se marcaron los modelos para que los usuarios reconozcan las estructuras individuales. Tanto la mesa y el programa libre tenían características respectivas para mejorar la experiencia de disección virtual. La mesa incluía el hardware designado con la pantalla de tamaño natural, mientras que el programa VK podía ser ejecutado en cualquier ordenador personal sin dificultad alguna. La coexistencia de la mesa y el programa libre pueden ser un apoyo importante para quienes estudien anatomía. Con el aumento de los datos de VK y el programa libre, se espera que exista una mayor cantidad de productos comerciales o gratuitos.

PALABRAS CLAVE: Proyectos humanos visibles; Modelos anatómicos; Simulacro computacional; Cadáver.

\section{REFERENCES}

Bessaud, J. C. \& Hersch, R. D. Visible Human slice sequence animation web server. Bethesda, The 3rd Visible Human Project Conference, 2000.

Bichlmeier, C.; Ockert, B.; Heining, S. M.; Ahmadi, A. \& Navab, N. Stepping into the operating theater: ARAV-Augmented reality aided vertebroplasty. Santa Barbara, Proc. 7th IEEE/
ACM Int. Symp. Mixed and Augmented Reality (ISMAR '08), 2008. pp.165-6.

Dai, J. X.; Chung, M. S.; Qu, R. M.; Yuan, L.; Liu, S. W. \& Shin, D. S. The Visible Human Projects in Korea and China with improved images and diverse applications. Surg. Radiol. Anat., 34(6):527-34, 2012. 
CHUNG, B. S.; SHIN, D. S.; BROWN, P.; CHOI, J. \& CHUNG, M. S. Virtual dissection table including the Visible Korean images, complemented by free software of the same data. Int. J. Morphol., 33(2):440-445, 2015.

Färber, M.; Hummel, F.; Gerloff, C. \& Handels, H. Virtual reality simulator for the training of lumbar punctures. Methods Inf. Med., 48(5):493-501, 2009.

Fyfe, G.; Fyfe, S. D.; Dye, D. E. \& Radley-Crabb, H. G. Use of Anatomage tables in a large first year core unit. Sydney, 30th Ascilite Conference 2013, Macquarie University, 2013. pp.298302.

Park, J. S.; Chung, M. S.; Hwang, S. B.; Lee, Y. S.; Har, D. H. \& Park, H. S. Visible Korean Human: improved serially sectioned images of the entire body. I. E. E. E. Trans. Med. Imaging, 24(3):352-60, 2005.

Shin, D. S.; Chung, M. S.; Park, H. S.; Park, J. S. \& Hwang, S. B. Browsing software of the Visible Korean data used for teaching sectional anatomy. Anat. Sci. Educ., 4(6):327-32, 2011.

Shin, D. S.; Chung, M. S. \& Park, J. S. Systematized methods of surface reconstruction from the serial sectioned images of a cadaver head. J. Craniofac. Surg., 23(1):190-4, 2012a.

Shin, D. S.; Chung, M. S.; Park, J. S.; Park, H. S.; Lee, S.; Moon, Y. L. \& Jang, H. G. Portable document format file showing the surface models of cadaver whole body. J. Korean Med. Sci., 27(8):849-56, 2012b.

Shin, D. S.; Jang, H. G.; Hwang, S. B.; Har, D. H.; Moon, Y. L. \& Chung, M. S. Two-dimensional sectioned images and threedimensional surface models for learning the anatomy of the female pelvis. Anat. Sci. Educ., 6(5):316-23, 2013.

Shin, D. S.; Park, J. S.; Park, H. S.; Hwang, S. B. \& Chung, M. S. Outlining of the detailed structures in sectioned images from Visible Korean. Surg. Radiol. Anat., 34(3):235-47, 2012c.

Spitzer, V.; Ackerman, M. J.; Scherzinger, A. L. \& Whitlock, D. The Visible Human male: a technical report. J. Am. Med. Inform. Assoc., 3(2):118-30, 1996.

Tang, L.; Chung, M. S.; Liu, Q. \& Shin, D. S. Advanced features of whole body sectioned images: Virtual Chinese Human. Clin. Anat., 23(5):523-9, 2010.

Uhl, J. F.; Park, J. S.; Chung, M. S. \& Delmas, V. Three-dimensional reconstruction of urogenital tract from Visible Korean Human. Anat. Rec. A Discov. Mol. Cell Evol. Biol., 288(8):8939, 2006.

Wetzel, A.; Athey, B.; Bookstein, F.; Green, W. \& Ade, A. Representation and performance issues in navigating Visible Human datasets. Bethesda, Proc. Third Visible Human Project Conference, NLM/NIH, 2000.

Zhang, S. X.; Heng, P. A. \& Liu, Z. J. Chinese Visible Human project. Clin. Anat., 19(3):204-15, 2006.

\section{Correspondence to: \\ Min Suk Chung \\ Department of Anatomy \\ Ajou University School of Medicine \\ 164 Worldcup-ro \\ Suwon 443-380 \\ REPUBLIC OF KOREA}

Tel.: +82-10-6474-1448

Fax.: +82-31-219-5039

Email: dissect@ajou.ac.kr

Received: 06-01-2015

Accepted: 24-03-2015 